\title{
Reservoir characterization of the thick IVF Cypress Sandstone in Noble Field, Illinois, for nonconventional $\mathrm{CO}_{2}$-EOR
}

\author{
Nathan D. Webb and Nathan P. Grigsby \\ Illinois State Geological Survey
}

North Central GSA Meeting

Champaign, IL

April 19, 2016

$\mathbb{1}_{\text {I L L I N O I S }}$ 


\section{Outline}

$\diamond$ Background

$\diamond$ Noble Field

$\diamond$ Geology

$\diamond$ Geocellular Modeling

$\diamond$ Preliminary Findings

$\diamond$ Implications and Future Work 


\section{Background: Motivation for study}

$\Delta$ Oil zones in the top of thick sandstones are a target for $\mathrm{CO}_{2}$-EOR and geologic storage

$\diamond$ EOR: Conventional reservoir and possible residual oil zone (ROZ)

$\diamond$ Storage: Vast capacity in aquifer

$\diamond$ Objectives: 4-year study to...

$\diamond$ Develop a method to economically recover incremental oil while storing $\mathrm{CO}_{2}$ in the underlying aquifer

$\diamond$ Identify ROZs by looking for direct and indirect indicators

$\diamond$ Direct: Oil saturation profiles from core or log analysis

$\diamond$ Indirect: Tilted oil/water contact, relatively fresh water, different oil composition

$\diamond$ Determine potential for net carbon negative oil production 


\section{Background: Cypress Ss Provinces}

$\diamond$ Multiple Cypress Sandstone provinces in the Illinois Basin

$\diamond$ Production commonly from sandstone lenses

$\diamond$ Oil zones in thick Cypress Ss

$\diamond$ Mobile oil above thick $(100+$ feet) saline aquifer

$\diamond$ Fining upward/increasing permeability with depth (?)

$\diamond$ Potential residual oil zones

$\diamond$ Naturally waterflooded over geologic time

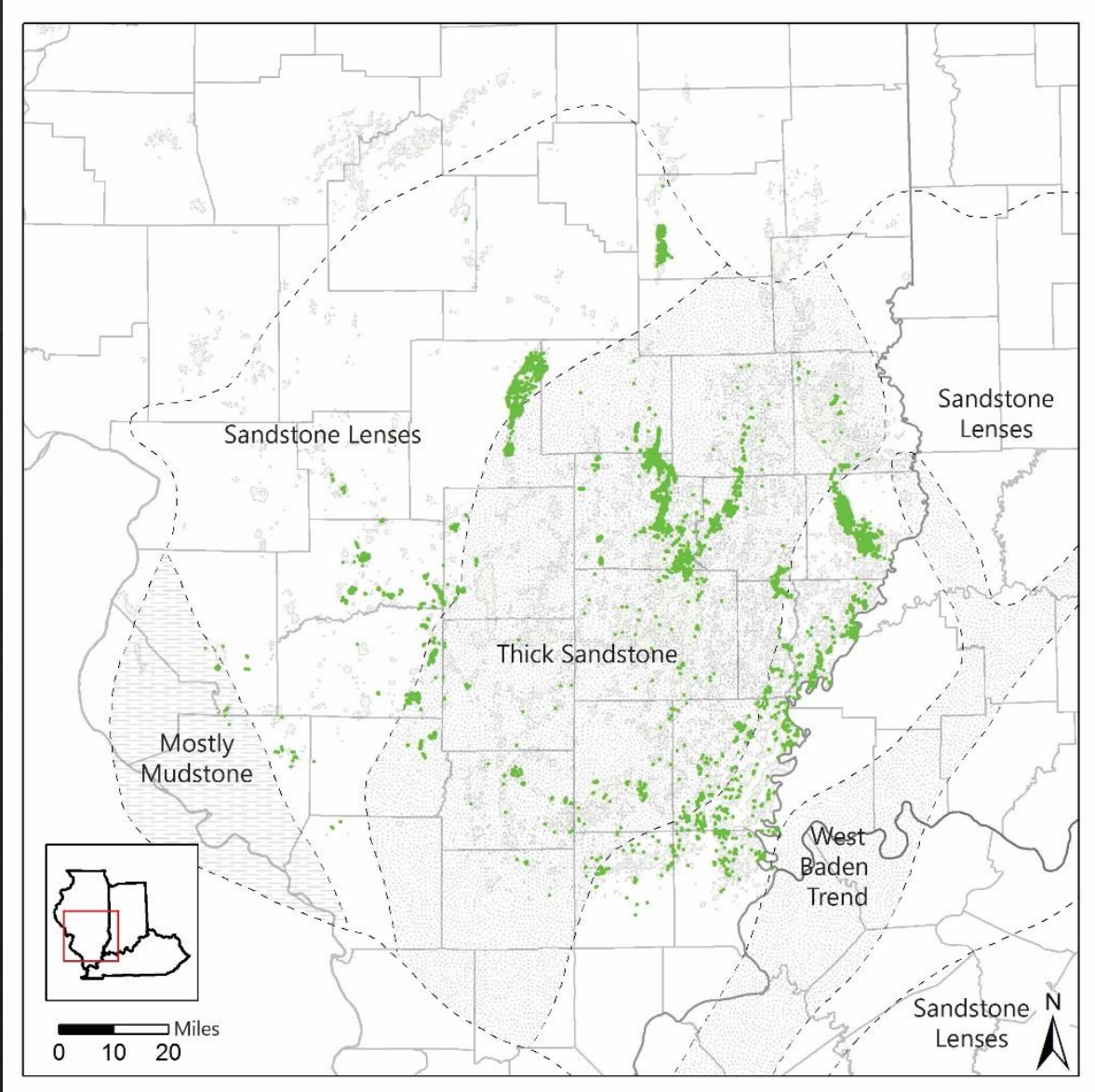

Cypress Sandstone provinces with Cypress producing wells in Illinois shown in green 


\section{Background: Thick Cypress Reservoirs}

$\diamond$ Nonconventional $\mathrm{CO}_{2}$-EOR

$\diamond$ Bypassed resource due to production difficulty

$\diamond$ Potential ROZ and high net $\mathrm{CO}_{2}$ utilization

$\otimes$ Saline storage potential of 3.5 to 40.2 Tcf ( 0.2 to 2.3 $\mathrm{Gt})^{*}$ of $\mathrm{CO}_{2}$ in the Illinois Basin (DOE/MGSC, 2012)

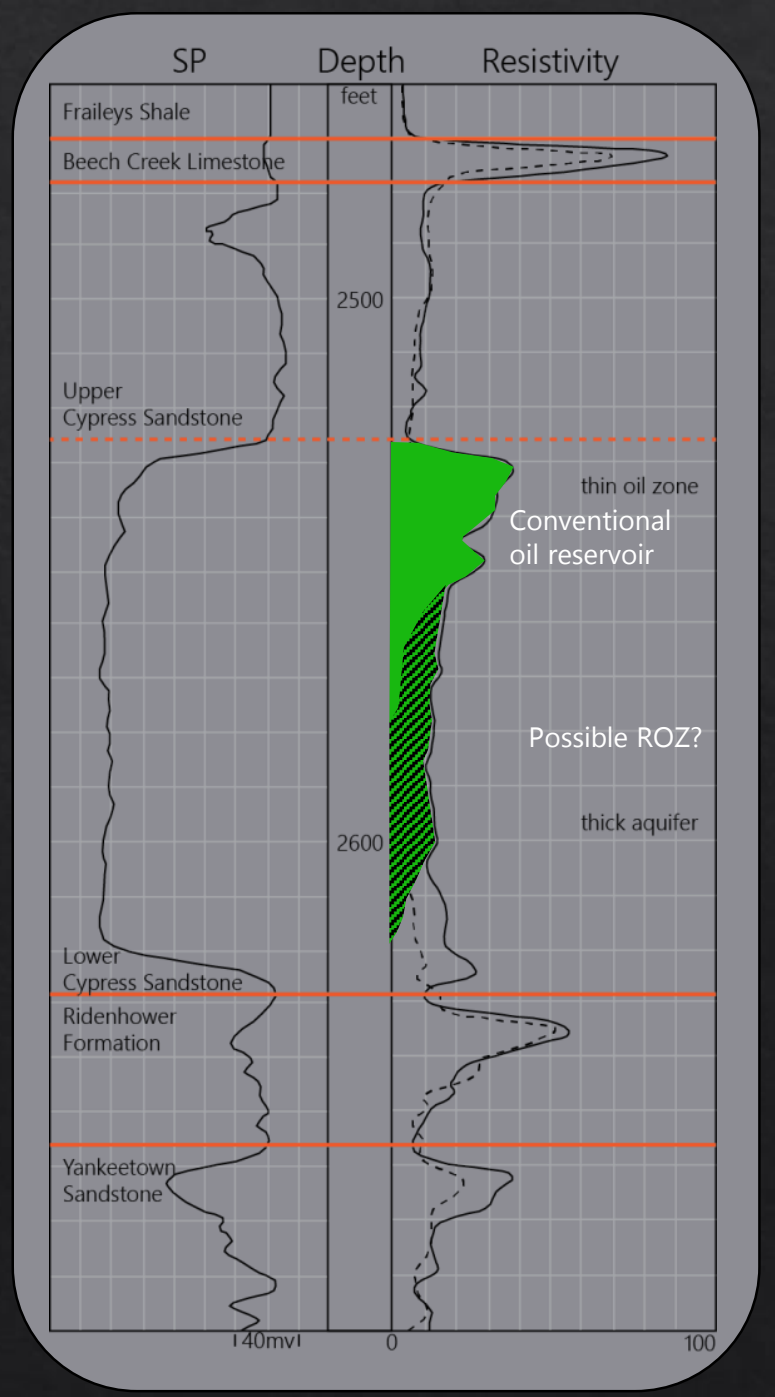




\section{Background: Historical Field Development}

$\diamond$ Vertical wells, natural open-hole completions

$\diamond$ Low oil recoveries due to excessive water coning

$\diamond$ Generally primary production only; some "waterflooding" (disposal of produced water)

$\diamond$ Polymer injection to block water (undocumented)

$\diamond$ Horizontal wells drilled in the last few decades

$\diamond$ No substantive long-term EOR attempts

$\diamond$ Few areas of the Basin where thick Cypress

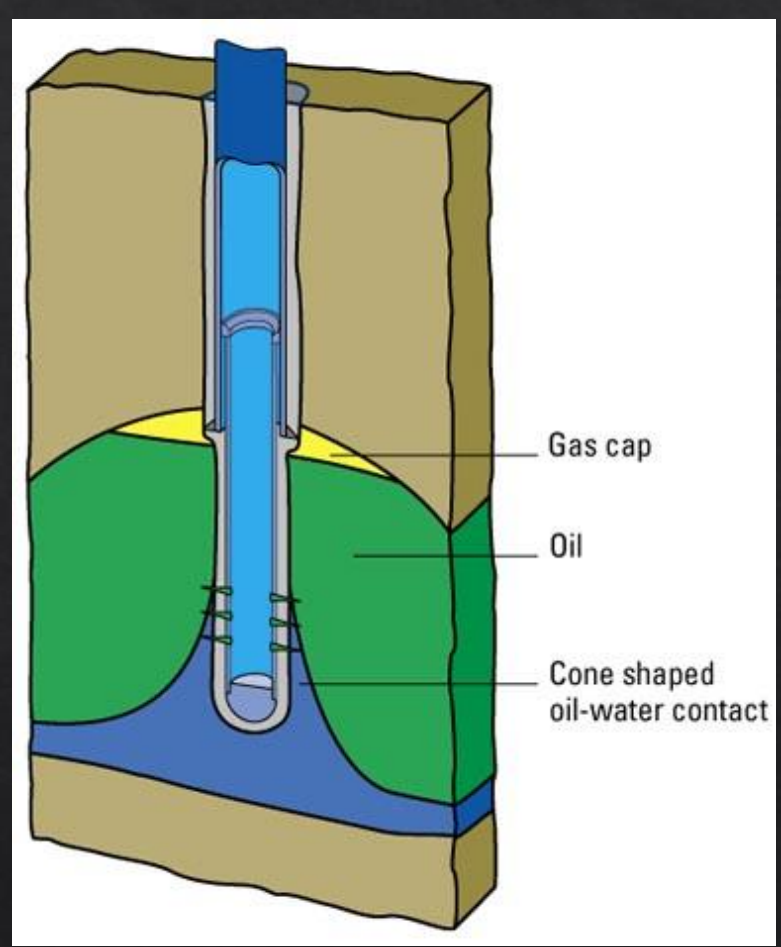
Sandstone is a prolific producer; Noble Field is the best example 


\section{Noble Field Location}

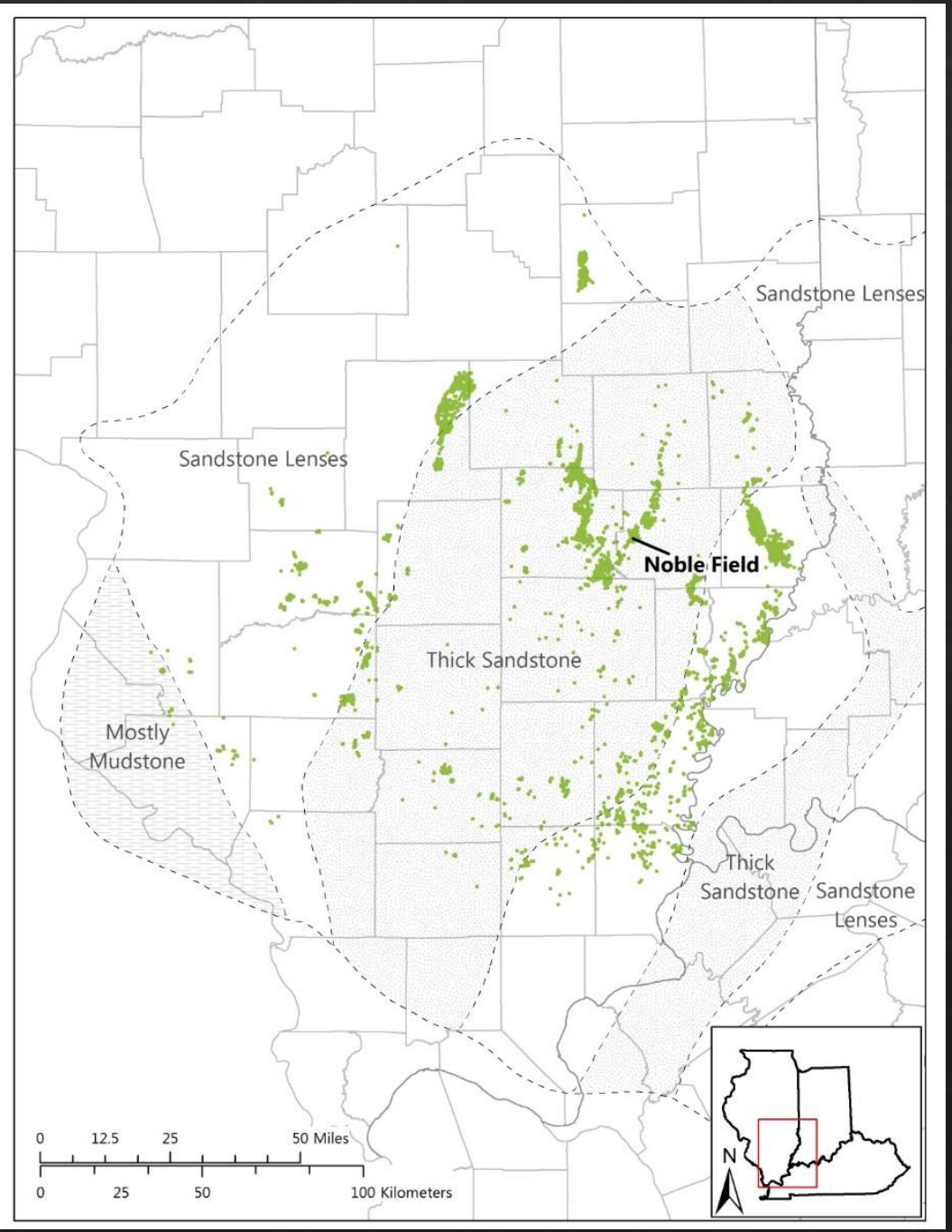

$\diamond$ Discovered in 1937 by Pure Oil

$\diamond$ Part of Clay City Consolidated Field

$\diamond 5$ main producing formations

$\diamond$ All are Mississippian in age

$\diamond$ Produced $>45 \mathrm{MMBO}$

$\diamond$ Thick Cypress Sandstone is a major producer 


\section{Geologic Setting}

$\diamond$ Cypress up to $\sim 175$ feet thick

$\diamond$ Field is located on SW plunging nose of the Clay City Anticline
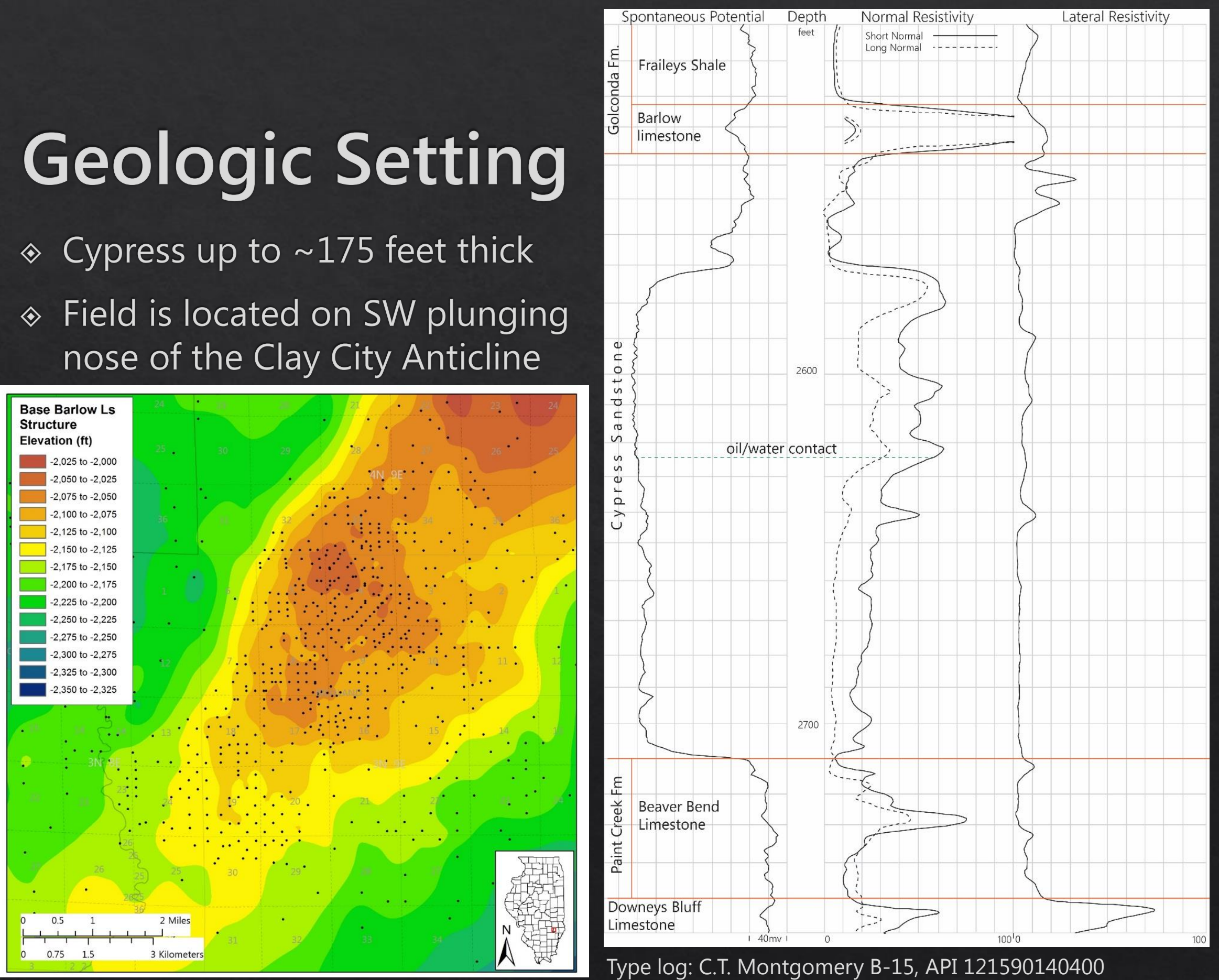

Type log: C.T. Montgomery B-15, API 121590140400 


\section{Cross Section Correlations}

$\diamond$ Well defined, blocky appearance on SP logs

$\diamond$ Laterally continuous easy correlation

$\diamond$ Few internal baffles

$\diamond$ Some continuous shale breaks

$\diamond$ Persistent calcitecemented zones

$\diamond$ Base of sandstone can truncate underlying units

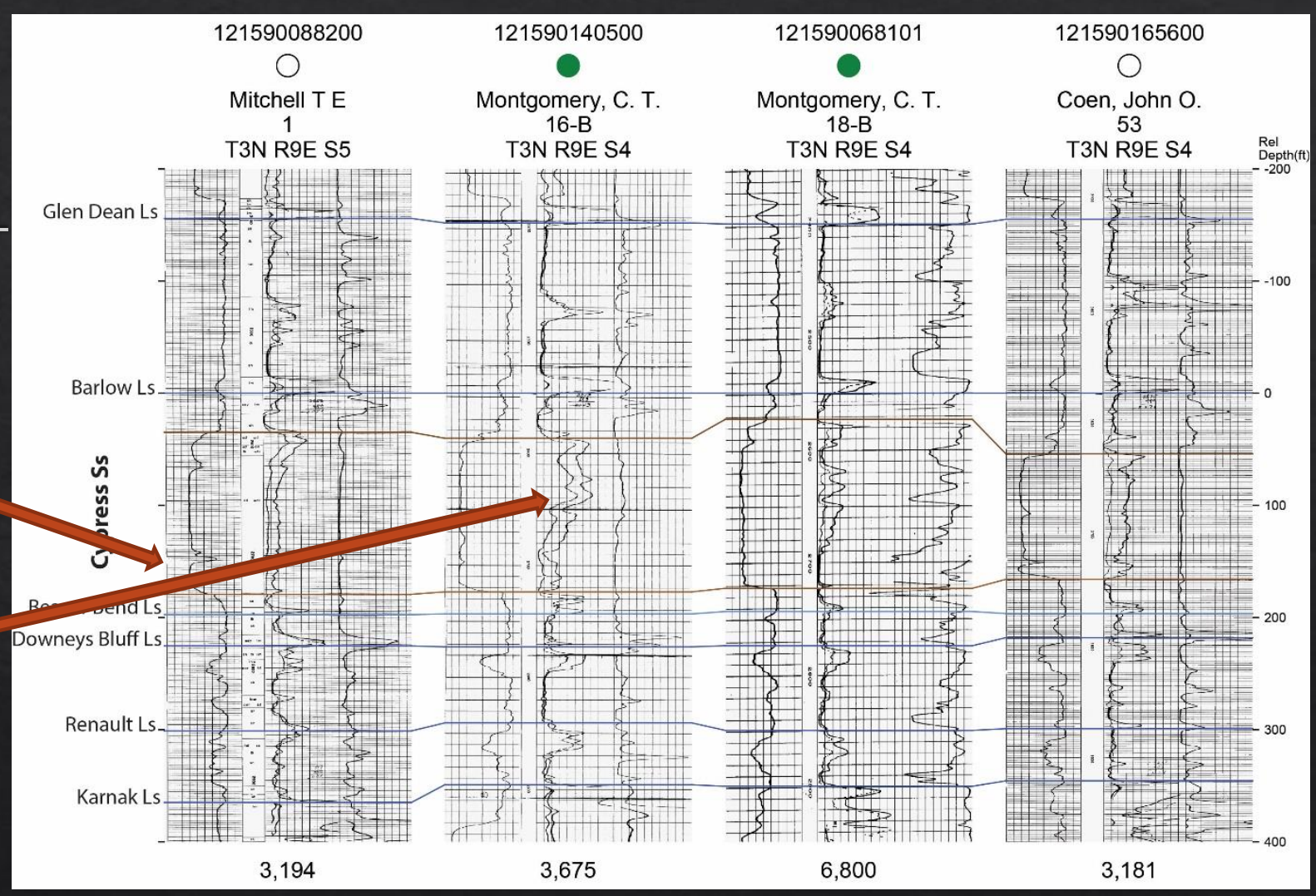

East-west log cross section 


\section{Cypress Sandstone Geometry}

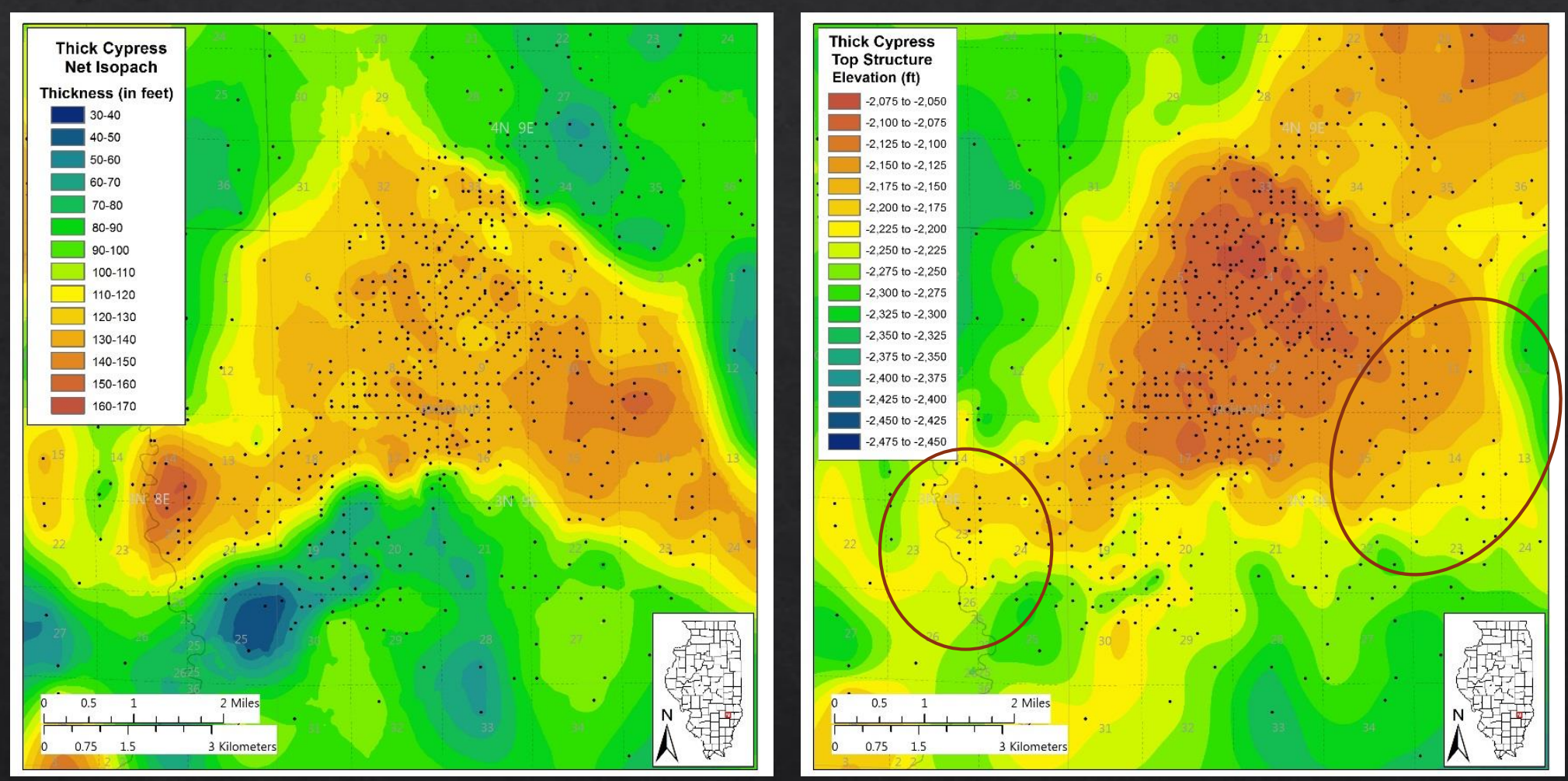

$\diamond$ Isopach shows intersecting NW-SE and NE-SW trending sandstone bodies

$\diamond$ Thickest sandstone occurs on the flanks of the Clay City Anticline

$\diamond$ Structure on top of sandstone shows effects of differential compaction 


\section{Cypress Sandstone Oil Reservoir}
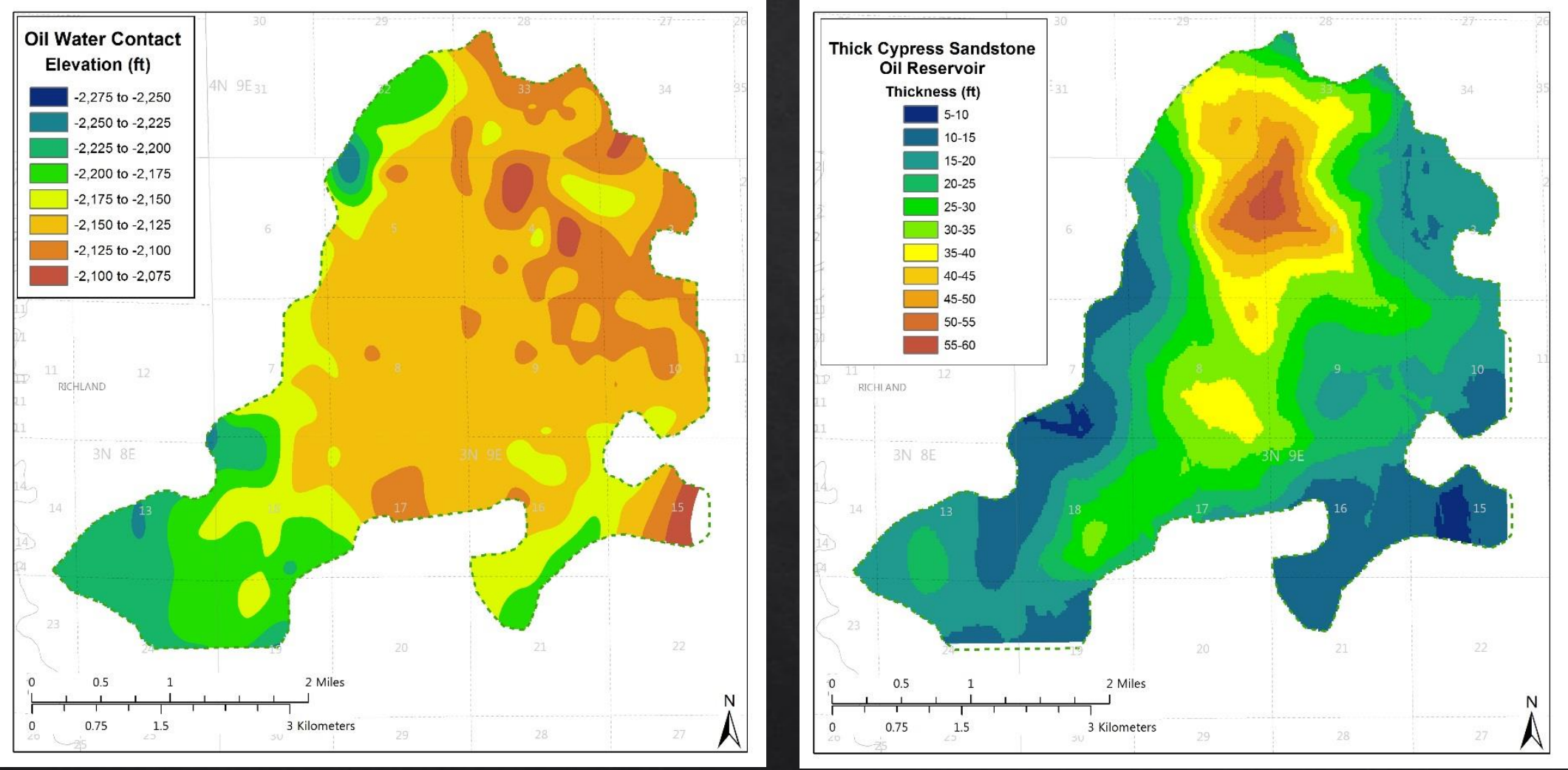

$\diamond$ Tilted oil/water contact (OWC) indicates possible ROZ

$\diamond$ Isopach of reservoir above OWC shows down-structure oil

$\diamond$ Preliminary OOIP of Cypress Ss $\sim 100 \mathrm{MMBO}$ without ROZ

$\diamond \sim 24 \mathrm{MMBO}$ Cypress production $=$ Recovery efficiency of $\sim 24 \%$ 


\section{Sedimentology}

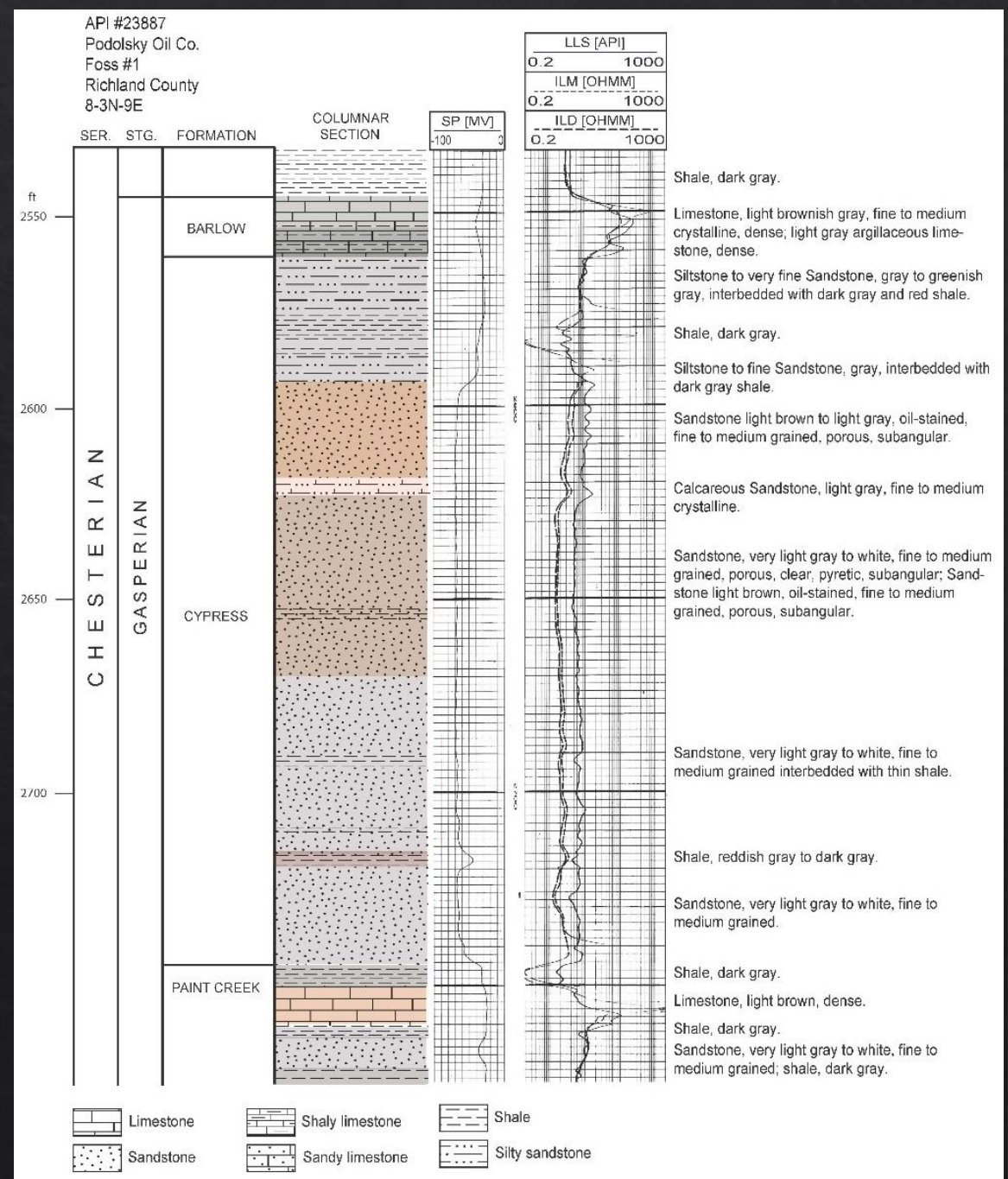

$\diamond$ Examining sample sets in and near Noble Field

$\diamond$ Fine- to medium-grained sandstone; not consistently fining upward

$\Delta$ Describing characteristics of internal baffles

$\diamond$ Laterally persistent, fossiliferous shale interbeds

$\diamond$ Dense, calcite-cemented sandstone intervals 


\section{Depositional Environment}

$\diamond$ The Cypress Sandstone at Noble Field is likely part of a lowstand (LST) incised valley fill environment

$\diamond$ Multistory sandstone built through parasequence-scale successive fluvial to estuarine depositional episodes

ه Amalgamated fluvial to estuarine channels are punctuated by marine incursions as indicated by fossil fragments

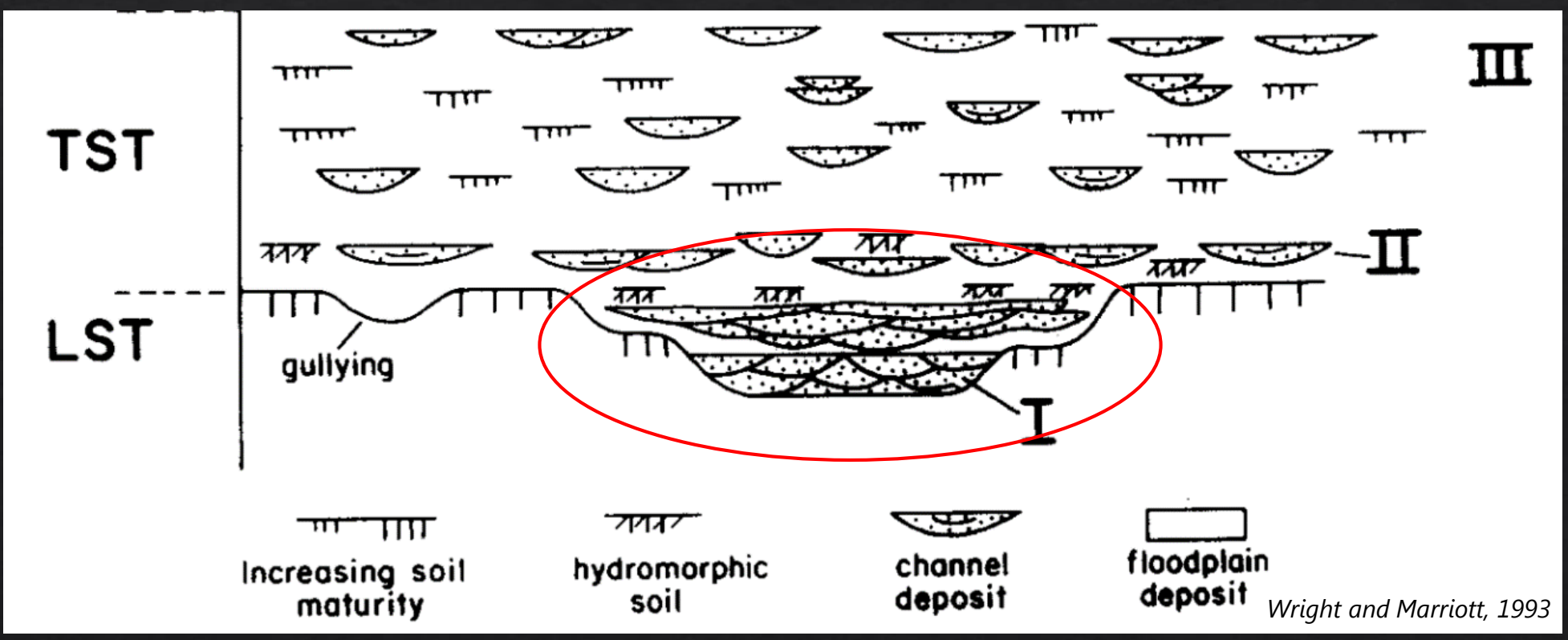




\section{Geological Model}

ه Basal sandstone story blankets entire field and reportedly covers much of the nearby counties; indicates low accommodation

$\diamond$ Middle and upper sandstone stories amalgamate at Noble Field but are less persistent elsewhere

$\diamond$ Top of thick Cypress Ss is convex upward where amalgamated

$\diamond$ Differential compaction over amalgamated sandstones create stratigraphic traps

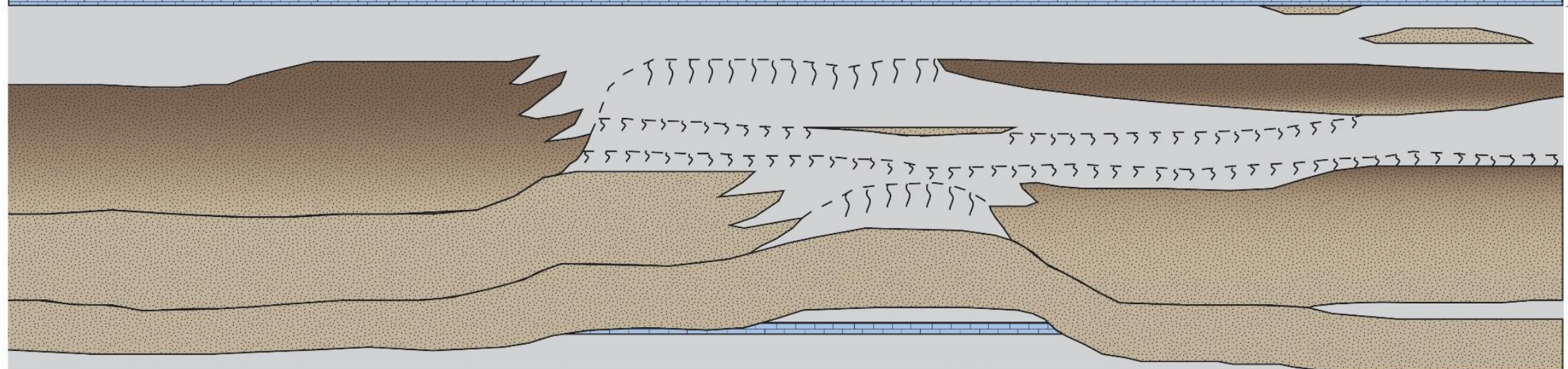




\section{Geocellular Model}

$\diamond \mathrm{SP}$ and neutrondensity logs were used to incorporate depositional and diagenetic facies

$\diamond$ Shaly, estuarine facies at the top of the model

$\diamond$ Thin shale interbeds

$\diamond$ Low porosity calcitecemented sandstone zones

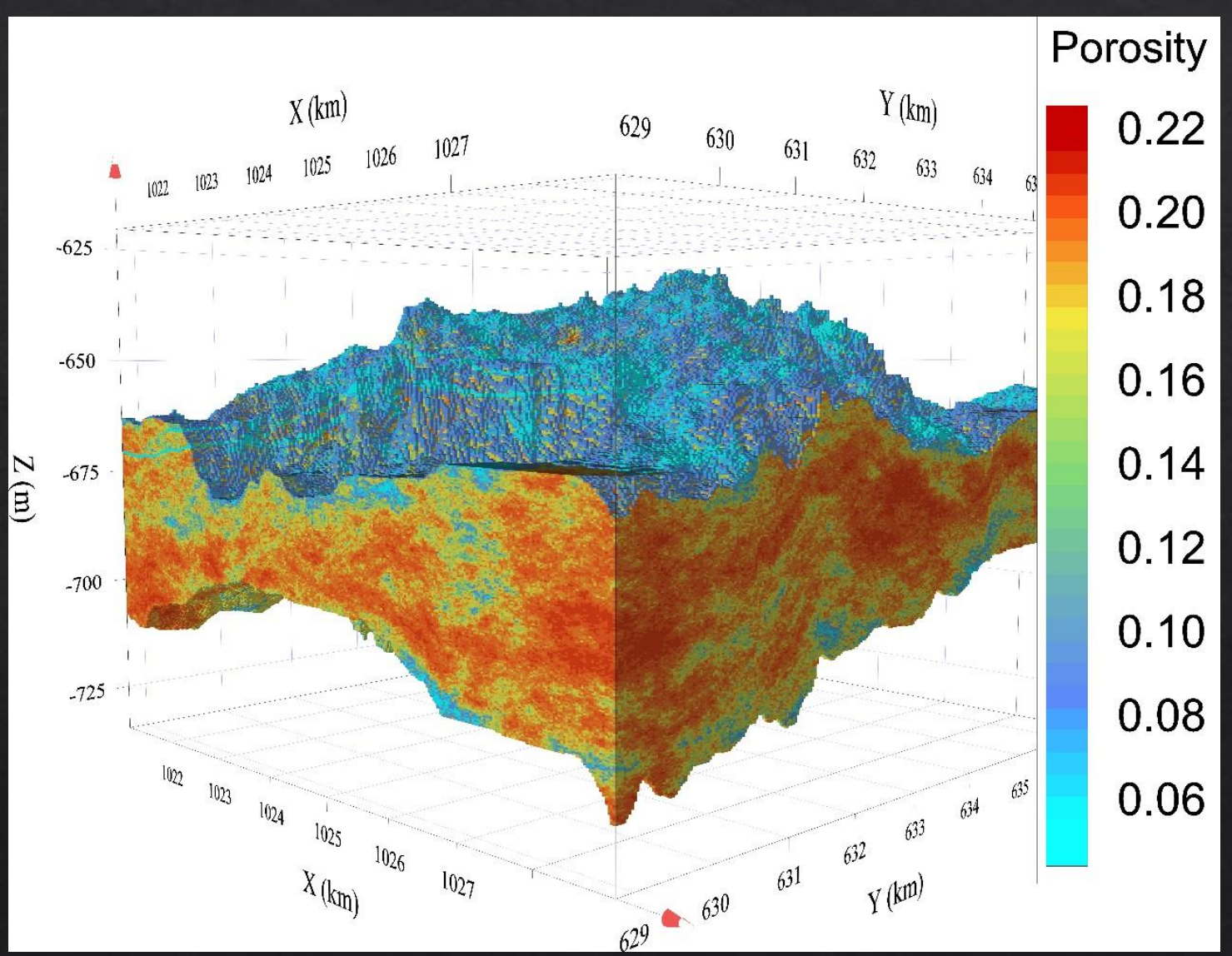




\section{Noble Field: Findings}

$\Delta$ Cypress Sandstone contributed $\sim 50 \%$ of cumulative production

$\diamond$ Combination of structural and stratigraphic controls on oil trapping

$\diamond$ Oil column up to $\sim 60$ feet thick with potential for underlying ROZ

$\diamond$ Oil/water contact is tilted towards the south

$\diamond$ Multistory fluvial/estuarine sandstone bodies make up the thick Cypress Sandstone

$\diamond$ Geocellular model captures anisotropy and sand/shale heterogeneity but needs further refining to include diagenetic features 


\section{Implications and Future Work}

$\diamond$ Noble Field has thickest known oil column and $<25 \%$ recovery efficiency - potential for $\mathrm{ROZ}$ and successful $\mathrm{CO}_{2}$-EOR

$\diamond$ Reservoir simulations to determine the most effective $\mathrm{CO}_{2}$-EOR and storage method

$\diamond$ Scenarios weighted towards oil production and storage

$\diamond$ Potential to produce net carbon negative oil (NCNO)

$\diamond$ Regional resource estimate using lessons learned from Noble Field

$\diamond$ Better understanding of the geology of the thick Cypress Sandstone

$\diamond$ Regional mapping of the thick Cypress Sandstone

$\diamond$ Identification of locations with oil reservoirs analogous to Noble Field

$\diamond$ Refine algorithm for identifying ROZs

ه Petrophysical methods supported by cased-hole pulsed-neutron logging, measuring saturation in fresh core, measuring oil and water composition 


\section{Acknowledgements}

$\Delta$ Research herein was supported by the US Department of Energy contract number DE-FE0024431

$\diamond$ Through a university grant program, IHS Petra software was used for the geologic modeling and Geovariances Isatis software was used for geocellular modeling

$\diamond$ For project information, including reports and presentations, please visit:

http://www.isgs.illinois.edu/research/oil-gas/doe

\section{References}

Wright, V. P., \& Marriott, S. B. (1993). The sequence stratigraphy of fluvial depositional systems: the role of floodplain sediment storage. Sedimentary Geology, 86, 203-210. 